\title{
Use of Topical Tranexamic Acid to Reduce Blood Loss in Single-Level Transforaminal Lumbar Interbody Fusion
}

\author{
Abhinandan Reddy Mallepally, Rajat Mahajan, Tarush Rustagi, \\ Shakti Amar Goel, Kalidutta Das, Harvinder Singh Chhabra \\ Department of Spine Services, Indian Spinal Injuries Centre, New Delhi, India
}

Study Design: Nonrandomized, prospective, and case-controlled study.

Purpose: To evaluate the efficacy and cost-effectiveness of topically applied tranexamic acid (TXA) during different phases of spine surgery.

Overview of Literature: Perioperative blood loss is the leading cause of postoperative anemia associated with prolonged stays in hospital and long recovery times. The direct and indirect costs involved pose a significant economic challenge in developing countries. There is no consensus for topical use of tranexamic acid in spine surgery.

Methods: Patients requiring a single-level TLIF were divided into two groups. In the TXA group ( $n=75)$, the wound surface was soaked with TXA (1 g in $100 \mathrm{~mL}$ saline solution) for 3 minutes after exposure, after decompression, and before wound closure, and in the control group ( $n=175$ ) using only saline. Intraoperative blood loss drain volume was recorded on each of the first 2 days immediately after surgery. An estimated cost analysis was made on the basis of the length of hospital stay and the blood transfusion.

Results: IBL for the control group was $783.33 \pm 332.71 \mathrm{~mL}$ and for intervention group $410.57 \pm 189.72 \mathrm{~mL}(p<0.001)$. The operative time for control group was $3.24 \pm 0.38$ hours and for intervention group $2.99 \pm 0.79$ hours $(p<0.695)$. Hemovac drainage on days 1 and 2 for control group was $167.10 \pm 53.83 \mathrm{~mL}$ and $99.33 \pm 37.5 \mathrm{~mL}$, respectively, and for intervention group $107.03 \pm 44.37 \mathrm{~mL}$ and $53.38 \pm 21.99$ $\mathrm{mL}$, respectively $(p<0.001)$. The length of stay was significantly shorter in the intervention group ( $4.8 \pm 1.1$ days) compared to control group (7.0 \pm 2.3 days). The cost of treatment in the intervention group was US dollar (USD) 4,552.57 $\pm 1,222.6$ compared with that in the control group USD 6,529.9 $91,505.04$.

Conclusions: Topical TXA is a viable, cost-effective method of decreasing perioperative blood loss in major spine surgery with fewer overall complications than other methods. Further studies are required to find the ideal dosage and timing.

Keywords: Spine surgery; Topical; Tranexamic acid; Surgical blood loss; Cost-effectiveness

\section{Introduction}

Perioperative blood loss can have a profound impact on the postoperative course following major spine surgery [1]. Fusion surgery requires wide exposure, including retracting paraspinal musculature, which may be associated with

Received May 1, 2019; Revised Sep 26, 2019; Accepted Oct 23, 2019

Corresponding author: Abhinandan Reddy Mallepally

Department of Spine Services, Indian Spinal Injuries Centre, Vasant Kunj, Sector C, New Delhi, Delhi-110070, India

Tel: +91-011-42255356,+918686598876, Fax: +91-011-42255243, E-mail: mabhi28@gmail.com 
bleeding, especially from venous channels. The associated blood loss causes increased operative time, complications, and, at times, necessitates a blood transfusion, which carries its own risks [2].

Despite advances in neuro-anesthesia and the adoption of various hemostatic techniques/agents, perioperative blood loss is the leading cause of postoperative anemia, which is associated with prolonged lengths of stay and recovery times $[3,4]$. The direct and indirect costs involved can pose a significant economic challenge, especially in developing and underdeveloped countries.

The use of systemic tranexamic acid (TXA), though a standard treatment in various orthopedic and cardiac surgeries, can have adverse effects, e.g., deep vein thrombosis, pulmonary embolism, epileptogenic activity, and myocardial infarction [5]. Prolonged operative time (especially in spine surgery) has a higher rate of these complications [5]. In recent years, reducing perioperative blood loss and transfusions in spine surgery has become increasingly important, and various studies have explored the efficacy of topically applied TXA at the surgical site [6-20]. Topical TXA has the advantage of direct and high local concentration at the bleeding site, and the risks associated with systemic administration are avoided. Although a few studies have looked at spine surgery [21-23], there is no consensus for its topical use in this field.

In this study, we evaluated the efficacy of topically applied TXA during different phases of single-level posterior lumbar fusion surgery and the cost-effectiveness of this treatment.

\section{Materials and Methods}

\section{Patients}

A nonrandomized, prospective, case controlled clinical study was conducted, which was approved by the Institutional Review Board of Indian Spinal Injuries Center (IRB approval no., ISIC/RP/2019/045). Informed consent was obtained from all the individual participants included in the study. The study cases were patients diagnosed between November 2017 and October 2018 with degenerative spine ailments requiring a single-level transforaminal lumbar interbody fusion. Those diagnosed within the first four of the study period months (November 2017 to February 2018) were placed in a control group, and those seen in the remaining 8 months (March 2018 to October
2018) formed the intervention group. Our tertiary care center ran a "patient pool" from which we were able to recruit subjects in a 2:1 ratio for the study. For every one control group patient we selected nearly two intervention group patients. From this resource, we invited all those available during the proposed study period. The patients in our study all had spinal degenerative diseases, including spinal stenosis, disc diseases, and unstable grades III spondylolisthesis indicated for surgical management. Patients with revision surgeries, osteoporosis (dualenergy X-ray absorptiometry less than -2.5), renal failure, seizures, chronic kidney disease, pulmonary embolism, deep vein thrombosis, bleeding disorders, an abnormal coagulation profile, a previous history of thromboembolic episodes, or on antiplatelet medication were excluded. The participants were divided into two groups: group 1 (those with whom we would apply topical TXA solution [the TXA group]) and group 2 (those who would be treated with saline solution alone [the control group]). The operating surgeon was blinded regarding the details of the solution. For this study, the surgery was shared by two senior surgeons.

After general anesthesia, patients were placed in a prone position over bolsters. Surgical steps included exposure over the operative site, including the transverse processes. This was followed by pedicle screw instrumentation, total laminectomy, facetectomy, lateral recess decompression, discectomy, end plate preparation, and interbody spacer insertion. In the TXA group, the wound surface (epidural space, lateral gutters, and muscle up to the skin level) was soaked with TXA ( $1 \mathrm{~g}$ in $100 \mathrm{~mL}$ saline solution) for 3 minutes after exposure, after decompression, and before wound closure. In the control group, the same volume of normal saline was used.

Intraoperative blood loss was calculated through the final volume in the suction containers minus the irrigated volume and the dry weight of the soaked sponges and gauze pieces used during the surgery. At the end of the procedure, the wound was closed over a negative suction drain. The operative duration was calculated as the time from the start of surgical incision to surgical site wound closure. The amounts of drain volume on postoperative Days 1 and 2 were recorded. The drain was removed when the output had been $<100 \mathrm{~mL}$ for 24 hours. Patient data collected included age, sex, operative time, intraoperative blood loss, drainage on postoperative days 1 and 2, day of drain removal, hematological parameters (hemoglobin, 
activated partial thromboplastin time, prothrombin time, international normalized ratio, and platelet count), and comorbid conditions of the patient. The influence of the hematological parameters and comorbid conditions on the amount of intraoperative blood loss and postoperative loss was evaluated. A cost estimate was made for the two groups based on the number of hospital days and costs involved in transfusion. The data regarding the number of extra days spent in the hospital, the requirement for transfusion, and the consequent extra money spent were also collected. The body mass index, height, and weight of the subjects were collected, and a statistical analysis was carried out. Complications were noted in both groups, including surgical site infections, wound dehiscence, re- admission from wound-related complications, and any medical compaction from the use of TXA.

\section{Statistical analysis}

The qualitative data were presented in percentage. The parametric quantitative data were presented as mean and standard deviations. A comparison between each of the two groups was analyzed using the Fisher exact test for qualitative data and the unpaired $t$-test for parametric quantitative data. A univariate analysis of risk factors and outcomes, along with a multivariate analysis of the regression of risk factors, was completed. All statistical analyses were performed using IBM SPSS software ver. 20.0 (IBM

Table 1. Patient characteristic and descriptive statistics

\begin{tabular}{|c|c|c|c|c|}
\hline Characteristic & Total & Intervention group & Control group & $p$-value \\
\hline Total & $250(100)$ & $175(70)$ & $75(30)$ & \\
\hline Age (yr) & $55.8 \pm 13.0(23-87)$ & $55.3 \pm 12.8(24-87)$ & $56.9 \pm 13.4(23-82)$ & 0.372 \\
\hline \multicolumn{5}{|l|}{ Gender } \\
\hline Male & $123(49.2)$ & 85 (48.6) & $39(52)$ & 0.622 \\
\hline Female & $127(50.8)$ & $90(51.4)$ & $36(48)$ & \\
\hline \multicolumn{5}{|l|}{ Level } \\
\hline L1-2 & $4(1.6)$ & $3(1.7)$ & $1(1.3)$ & \\
\hline L2-3 & $2(0.8)$ & $2(1.1)$ & $0(0.0)$ & \\
\hline L3-4 & $23(9.2)$ & $17(9.7)$ & $7(9.3)$ & 0.881 \\
\hline$\lfloor 4-5$ & $161(64.4)$ & $111(63.4)$ & $49(65.3)$ & \\
\hline L5-S1 & $60(24.0)$ & $42(24.0)$ & $18(24.0)$ & \\
\hline \multicolumn{5}{|l|}{ Diabetes mellitus } \\
\hline No & $166(66.4)$ & $117(66.9)$ & 49 (65.3) & 0.789 \\
\hline Yes & $84(33.6)$ & $58(33.1)$ & $26(34.7)$ & \\
\hline \multicolumn{5}{|l|}{ Hypertension } \\
\hline No & $142(56.8)$ & $96(54.8)$ & 49 (65.3) & 0.357 \\
\hline Yes & $108(43.2)$ & $79(45.2)$ & $26(34.7)$ & \\
\hline \multicolumn{5}{|l|}{ Drain removed on } \\
\hline Day 2 & $202(80.8)$ & $169(96.6)$ & $33(44.0)$ & \\
\hline Day 3 & $44(17.6)$ & $6(3.4)$ & $38(50.7)$ & $<0.001$ \\
\hline Day 4 & $4(1.6)$ & 0 & $4(5.3)$ & \\
\hline Prothrombin time (sec) & $13.1 \pm 1.1(10.5-16.6)$ & $13.1 \pm 1.1(10.7-16.6)$ & $13.0 \pm 1.1(10.5-16.2)$ & 0.887 \\
\hline Activated partial thromboplastin time (sec) & $26.7 \pm 3.4(3.9-38.6)$ & $26.6 \pm 3.1(18.9-37.7)$ & $26.7 \pm 4.1(3.9-38.6)$ & 0.812 \\
\hline International normalised ratio & $1.1 \pm 0.1(0.8-1.5)$ & $1.1 \pm 0.1(0.9-1.5)$ & $1.1 \pm 0.1(0.9-1.4)$ & 0.676 \\
\hline Hemoglobin (gm/dL) & $12.5 \pm 1.8(4.3-17.5)$ & $12.4 \pm 1.8(4.3-17.5)$ & $12.6 \pm 1.9(7.8-17.0)$ & 0.605 \\
\hline Platelet count (lakhs/mm³) & $2.4 \pm 0.8(1.1-6.3)$ & $2.5 \pm 0.8(1.1-6.3)$ & $2.2 \pm 0.6(1.3-4.4)$ & 0.054 \\
\hline Packed cell volume (mL) & $37.7 \pm 5.2(1.0-51.5)$ & $37.6 \pm 5.3(1.0-50.2)$ & $36.8 \pm 24.6(24.9-51.5)$ & 0.655 \\
\hline
\end{tabular}

Values are presented as number (\%) or mean \pm standard deviation (range). 
Corp., Armonk, NY, USA). The $p$-value of $<0.05$ was considered as statistically significant.

\section{Results}

A total of 250 patients who met the inclusion criteria participated in the study. There were 75 patients in the control group and 175 patients in the intervention group. No significant differences in sex, age, preoperative hematological parameters, or surgical level were present between the two groups. Patient characteristics and descriptive statistics are shown in Table 1.

Intraoperative blood loss for the control group was $783.33 \pm 332.71 \mathrm{~mL}$, and for the intervention group, it was $410.57 \pm 189.72 \mathrm{~mL}(p<0.001)$. The operative time for the control group was $3.24 \pm 0.38$ hours, and for the intervention group, it was $2.99 \pm 0.79$ hours $(p<0.695)$. The duration for the control group was comparable with that for the TXA group. The Hemovac drainage on day 1 for the control group was $167.10 \pm 53.83 \mathrm{~mL}$, and for the intervention group, it was $107.03 \pm 44.37 \mathrm{~mL}$, and the difference in the amounts of blood loss due to drainage on day 1 was statistically significant. The amount of drainage on day 2 was $99.33 \pm 37.5$ and $53.38 \pm 21.99 \mathrm{~mL}$ in the control and intervention groups, respectively. This difference was also statistically significant $(p<0.001)$.

Other variables such as hypertension (HTN), diabetes mellitus (DM), and hematological parameters were compared across groups, and associations with outcome variables were checked using Pearson's correlation coefficient. The blood-related parameters, HTN, and DM status were not associated with outcome variables. All three groups were comparable in terms of rates of wound problem incidences. No patient in either group was re-admitted because of postoperative complications. No adverse reaction to TXA was noted during the study. Outcomes and results are shown in Table 2.

The length of stay was significantly shorter in the intervention group (4.8 \pm 1.1 days) than that in the control group (7.0 \pm 2.3 days) (Fig. 1). There was a significant difference in the amounts of time spent on the treatment between the intervention group $(4,552.57 \pm 1,222.6$ hours) and control group $(6,529.9 \pm 1,505.04$ hours). Significant factors associated with patients in the intervention group

Table 2. Outcome characteristics of study subjects

\begin{tabular}{|c|c|c|}
\hline Characteristic & Intervention group & Control group \\
\hline Total patients & $175(70)$ & $75(30)$ \\
\hline \multicolumn{3}{|l|}{ Gender } \\
\hline Male & $85(48.9)$ & $40(51.9)$ \\
\hline Female & $90(51.1)$ & $35(48.1)$ \\
\hline \multicolumn{3}{|c|}{ Body mass index $\left(\mathrm{kg} / \mathrm{m}^{2}\right)$} \\
\hline Mean $\pm S D$ (range) & $24.4 \pm 2.31(17.5-30.3)$ & $24.3 \pm 2.09(18.3-29.7)$ \\
\hline Underweight & $2(1.1)$ & $1(1.3)$ \\
\hline Normal & $85(48.3)$ & $45(58.3)$ \\
\hline Obese & $89(50.6)$ & $31(40.3)$ \\
\hline \multicolumn{3}{|l|}{ Blood loss (mL) } \\
\hline Mean $\pm S D$ & $410.57 \pm 189.72$ & $783.33 \pm 332.71$ \\
\hline \multicolumn{3}{|l|}{ Length of stay (day) } \\
\hline Mean $\pm S D$ & $4.8 \pm 1.10$ & $7.0 \pm 2.30$ \\
\hline \multicolumn{3}{|l|}{ Operative time (hr) } \\
\hline Mean $\pm S D$ & $2.99 \pm 0.79$ & $3.24 \pm 0.38$ \\
\hline Median (range) & $3(2-7)$ & $3.2(2.5-8)$ \\
\hline \multicolumn{3}{|c|}{ Amount spent on treatment (US \$) } \\
\hline Mean $\pm S D$ & $4,552.57 \pm 1,222.6$ & $6,529.9 \pm 1,505.04$ \\
\hline Median (range) & $4,580(1,789-7,173)$ & $6,607(2,690-11,552)$ \\
\hline
\end{tabular}

Values are presented as number (\%), unless otherwise stated.

SD, standard deviation. 
as recognized by a univariate logistic regression analysis are shown in Table 2. In the univariate analysis, the length of stay in hospital (odds ratio [OR], 2.77), operative time (OR, 2.74), and amount of time spent on treatment/surgery $(\mathrm{OR}, 15,610.9)$ were found to be significant factors, whereas blood loss $(\mathrm{OR}, 1.20)$ only showed a trend toward significance. A multivariable logistic regression analysis revealed that the length of stay in hospital (OR, 2.35; 95\% confidence interval, 1.74-3.19; $p<0.001$ ) had significant association (Table 3). Patients who did not receive the intervention stayed in hospital 2.35 times longer than those who did (Tables 3, 4 and Fig. 1).

\section{Discussion}

In this case-controlled study, we found that use of topical TXA was associated with significantly less blood loss during and after surgery than using normal saline solution.

Substantial blood loss is common in major spine surgery. Excessive perioperative blood loss negatively affects patient outcomes and may be associated with increasing coagulopathy, postoperative hematoma, anemia, a need for blood transfusions with their associated risks, and prolonged hospitalization [1].

The economic burden can be heavy for patients in developing countries facing the direct and indirect costs of

Table 3. Multivariable logistic regression analysis to estimate treatment effects

\begin{tabular}{|c|c|c|}
\hline Variable & Odds ratio ( $95 \%$ confidence interval) & $p$-value ${ }^{\text {a) }}$ \\
\hline Blood loss & $0.88(0.59-1.14)$ & 0.401 \\
\hline Length of stay & $2.35(1.74-3.19)$ & 0.001 \\
\hline
\end{tabular}

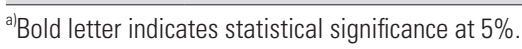

blood transfusions, prolonged hospital stays, and complications and their management. Following spine surgery, patients may be obliged to remain hospitalized only for the maintenance of surgical drains. TXA application reduces this time and decreases the likelihood of epidural hematoma.

With TXA, a synthetic lysine analog interferes with fibrinolysis. It acts by binding reversibly and competitively to lysine-binding domains on plasminogen, plasmin, and tissue plasminogen activators. It thereby decreases the conversion of plasminogen to active serine protease plasmin, which subsequently dissolves fibrin clots [24].

Administration of TXA into systemic circulation is

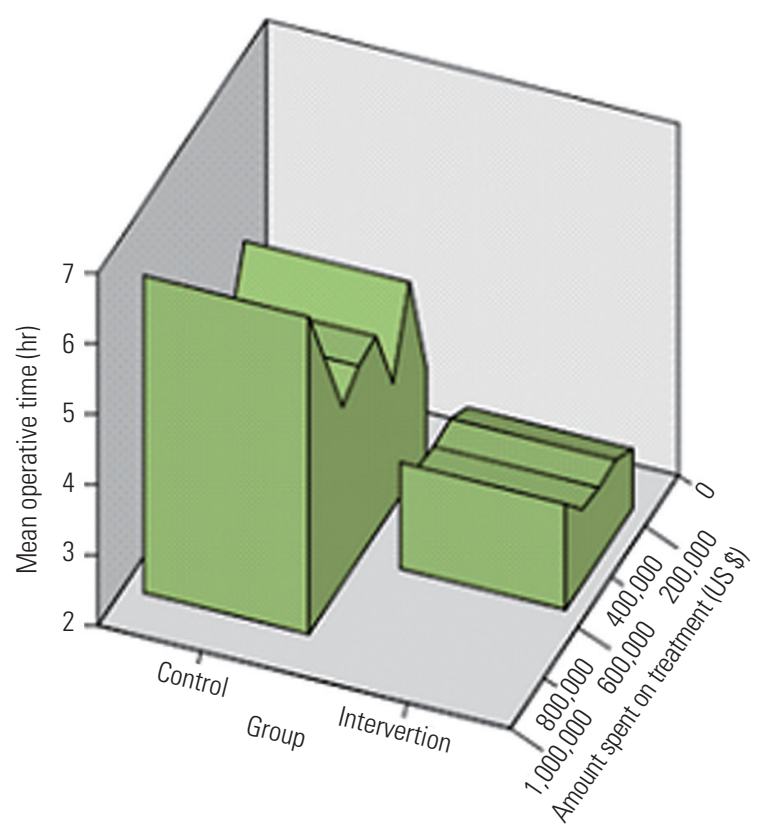

Fig. 1. Graph representing the operative time and cost incurred during hospital stay in the control and intervention groups.

Table 4. Univariate analysis to estimate treatment effects

\begin{tabular}{lccc}
\hline Variable & $\beta$ coefficient estimate \pm standard error & Odds ratio (95\% confidence interval) & $p$-value \\
\hline Gender (male) & $0.12 \pm 0.27$ & $1.13(0.66-1.93)$ & 0.652 \\
\hline Age & $0.01 \pm 0.01$ & $1.01(0.99-1.03)$ & 0.350 \\
\hline Co-morbidities (present) & $-0.24 \pm 0.27$ & $0.78(0.46-1.35)$ & 0.386 \\
\hline Blood loss & $0.18 \pm 0.09$ & $1.20(0.99-1.43)$ & 0.054 \\
\hline Length of stay & $1.01 \pm 0.15$ & $2.77(2.07-3.70)$ & $<0.001$ \\
\hline Operative time & $0.14 \pm 0.34$ & $1.44(0.66-1.83)$ & $<0.695$ \\
\hline Body mass index & $-0.02 \pm 0.06$ & $0.98(0.87-1.11)$ & 0.793 \\
Amount spent on treatment & $13.9 \pm 2.01$ & $15,610.9(305.4-797,865.65)$ & $<0.001$ \\
\hline
\end{tabular}

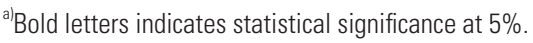


known to decrease perioperative blood loss and the need for blood products by one third in major operations, including spinal surgery [7]. It is eliminated via the renal route and hence requires a dose adjustment for renally impaired patients [25]. The "ideal" dosage for the intravenous route is still not agreed. Potential adverse effects include deep vein thrombosis, pulmonary embolism, epileptogenicity in susceptible patients (rare), visual disturbances, and acute renal necrosis $[5,26]$. These potential side effects have generated a new interest in TXA application for hemorrhage control, as the surgical site has maximum fibrinolysis activity and persists through the perioperative period. The role of topical TXA is well established in orthopedic reconstructive and cardiac surgeries $[8,9,11,12]$.

In this study, there was a substantial decrease in the intraoperative blood loss (47.7\%): drain output on day 1 was $35.93 \%$ and $45.7 \%$ on day 2 . The results of our study agree with others using TXA [27-29]. We further showed that the comorbid status of the patients, such as in DM and HTN, had no significant influence on intraoperative or postoperative blood loss. The hematological parameters were also not significant for the quantities of blood loss in the perioperative period. The advantages of TXA include ease of administration, high focal concentration in the surgical site (e.g., the cut ends of bones and epidural venous ooze can be attenuated by topical application of TXA), and minimal absorption into the systemic circulation.

In a systematic review by Ker et al. [27] involving 29 randomized clinical trials, with 2,612 patients, studying the effects of topical application of TXA in surgery, a $29 \%$ reduction in blood loss was reported, which was comparable with that for systemically administered TXA. They also concluded that the likelihood of receiving a blood product was decreased by $45 \%$ among 14 randomized control trials involving 1,523 patients. The Society of Thoracic Surgeons and the Society of Cardiovascular Anesthesiologists recommend both systemic and topical TXA as a standard of care for managing surgical bleeding [6].

In a placebo-controlled study, Krohn et al. [28] showed the effect of TXA on postoperative blood loss in patients with elective lumbar instrumented spinal fusion surgery (16 received topical TXA and 13 received a placebo). The median postoperative blood loss was reduced by half in patients in the topical TXA group (252 $\mathrm{mL}$ with topical TXA versus $525 \mathrm{~mL}$ without), demonstrating the locally sustained hemostatic efficacy of topical TXA. Requirement for blood transfusion was also reduced $(n=2)$ when compared with that in the placebo group $(n=9)$.

Similarly, a study by Saberi et al. [29], involving 50 patients with a unilateral one-level laminectomy and 50 patients with a bilateral two-level laminectomy, showed a significant decrease in drain output on postoperative days 1 and 2 . The effect was more profound on single-level unilateral surgeries. They also reported a decrease in the average hospital stay for the intervention group.

The present study also discusses the cost-effectiveness of decreasing perioperative blood loss using topical TXA. From the resources at our hospital, direct economic benefits can be estimated. TXA costs US dollar (USD) 1 for a 3-mg vial. Hemostatic agents cost nearly USD 200, with USD 100 for blood products and disposables along with an excess for increased length of stay at the hospital, which can pose a severe financial challenge to patients in developing countries. There was significant difference (nearly USD 2,000) between the intervention and control groups.

We did not see any perioperative complications in the TXA group. Indeed, there were no statistically significant differences in complication rates between the two groups.

The ideal time for topical application of TXA has not yet been settled in spine surgery, and its effect on intraoperative hemorrhage control is also yet to be established. Therefore, we decided to irrigate the surgical site during the point of maximum bleeding, i.e., after complete exposure, after decompression, and just before closure after the interbody spacer placement and rod insertion. The optimal dosage for topical application is also not yet agreed. To date, only saline-based irrigations have been used. The contact time and amount of absorption into the tissues of the locally available TXA are still not clear. Further studies are required to quantify the contact period, time of surgical procedure, local concentration, and optimal dose from local tissue samples.

Although the homogeneity of the patient groups who underwent a single-level instrumented interbody fusion by the same surgeon is a strength of the study, the present study had some limitations. First, this was a non-randomized case-controlled study; second, the patients were at relatively low risk; therefore, this treatment could not be applied to all patients undergoing complex spine surgery. The operations were carried out by two different surgeons and were not assumed to assess the decrease in require- 
ments of a blood transfusion.

\section{Conclusions}

Topical TXA is a viable and cost-effective method of decreasing perioperative blood loss in major spine surgery with fewer overall complications than other solutions. Further studies are required to find the ideal dosage and timing.

\section{Conflict of Interest}

No potential conflict of interest relevant to this article was reported.

\section{References}

1. Huang YH, Ou CY. Significant blood loss in lumbar fusion surgery for degenerative spine. World Neurosurg 2015;84:780-5.

2. Kumar A. Perioperative management of anemia: limits of blood transfusion and alternatives to it. Cleve Clin J Med 2009;76 Suppl 4:S112-8.

3. Dutton RP. Controlled hypotension for spinal surgery. Eur Spine J 2004;13 Suppl 1:S66-71.

4. Gill JB, Chin Y, Levin A, Feng D. The use of antifibrinolytic agents in spine surgery: a meta-analysis. J Bone Joint Surg Am 200;90:2399-407.

5. Yerneni K, Burke JF, Tuchman A, et al. Topical tranexamic acid in spinal surgery: a systematic review and meta-analysis. J Clin Neurosci 2019;61:1149.

6. Ipema HJ, Tanzi MG. Use of topical tranexamic acid or aminocaproic acid to prevent bleeding after major surgical procedures. Ann Pharmacother 2012;46:97107.

7. Winter SF, Santaguida C, Wong J, Fehlings MG. Systemic and topical use of tranexamic acid in spinal surgery: a systematic review. Global Spine J 2016;6:284-95.

8. Yen SH, Lin PC, Chen B, Huang CC, Wang JW. Topical tranexamic acid reduces blood loss in minimally invasive total knee arthroplasty receiving rivaroxaban. Biomed Res Int 2017;2017:9105645.

9. Zhu J, Zhu Y, Lei P, Zeng M, Su W, Hu Y. Efficacy and safety of tranexamic acid in total hip replacement: a PRISMA-compliant meta-analysis of 25 randomized controlled trials. Medicine (Baltimore) 2017;96:e9552.

10. George J, Eachempati KK, Subramanyam KN, Gurava Reddy AV. The comparative efficacy and safety of topical and intravenous tranexamic acid for reducing perioperative blood loss in total knee arthroplasty: a randomized controlled non-inferiority trial. Knee 2018;25:185-91.

11. Dell'Amore A, Caroli G, Nizar A, et al. Can topical application of tranexamic acid reduce blood loss in thoracic surgery?: a prospective randomised double blind investigation. Heart Lung Circ 2012;21:706-10.

12. Fawzy H, Elmistekawy E, Bonneau D, Latter D, Errett L. Can local application of tranexamic acid reduce post-coronary bypass surgery blood loss?: a randomized controlled trial. J Cardiothorac Surg 2009;4:25.

13. Wong J, Abrishami A, El Beheiry H, et al. Topical application of tranexamic acid reduces postoperative blood loss in total knee arthroplasty: a randomized, controlled trial. J Bone Joint Surg Am 2010;92:250313.

14. Patel JN, Spanyer JM, Smith LS, Huang J, Yakkanti MR, Malkani AL. Comparison of intravenous versus topical tranexamic acid in total knee arthroplasty: a prospective randomized study. J Arthroplasty 2014;29:1528-31.

15. Georgiadis AG, Muh SJ, Silverton CD, Weir RM, Laker MW. A prospective double-blind placebo controlled trial of topical tranexamic acid in total knee arthroplasty. J Arthroplasty 2013;28:78-82.

16. Konig G, Hamlin BR, Waters JH. Topical tranexamic acid reduces blood loss and transfusion rates in total hip and total knee arthroplasty. J Arthroplasty 2013;28:1473-6.

17. Chang CH, Chang Y, Chen DW, Ueng SW, Lee MS. Topical tranexamic acid reduces blood loss and transfusion rates associated with primary total hip arthroplasty. Clin Orthop Relat Res 2014;472:1552-7.

18. Gilbody J, Dhotar HS, Perruccio AV, Davey JR. Topical tranexamic acid reduces transfusion rates in total hip and knee arthroplasty. J Arthroplasty 2014;29:681-4.

19. Alshryda S, Sukeik M, Sarda P, Blenkinsopp J, Haddad FS, Mason JM. A systematic review and metaanalysis of the topical administration of tranexamic acid in total hip and knee replacement. Bone Joint J 2014;96-B:1005-15.

20. Sa-Ngasoongsong P, Channoom T, Kawinwong- 
gowit V, et al. Postoperative blood loss reduction in computer-assisted surgery total knee replacement by low dose intra-articular tranexamic acid injection together with 2-hour clamp drain: a prospective tripleblinded randomized controlled trial. Orthop Rev (Pavia) 2011;3:e12.

21. U.S. National Library of Medicine. Effectiveness Study of the Drug Tranexamic Acid to Reduce Postsurgery Blood Loss in Spinal Surgery: ClinicalTrials. gov: NCT02063035 [Internet]. Bethesda (MD): U.S. National Library of Medicine; 2017 [cited 2019 May 20]. Available from: https://clinicaltrials.gov/ct2/ show/NCT02063035.

22. Liang J, Liu $\mathrm{H}$, Huang $\mathrm{X}$, et al. Using tranexamic acid soaked absorbable gelatin sponge following complex posterior lumbar spine surgery: a randomized control trial. Clin Neurol Neurosurg 2016;147:110-4.

23. Sudprasert W, Tanaviriyachai T, Choovongkomol K, Jongkittanakul S, Piyapromdee U. A randomized controlled trial of topical application of tranexamic acid in patients with thoracolumbar spine trauma undergoing long-segment instrumented posterior spinal fusion. Asian Spine J 2019;13:146-54.

24. McCormack PL. Tranexamic acid: a review of its use in the treatment of hyperfibrinolysis. Drugs 2012;72:585-617.

25. Cyklokapron (tranexamic acid). Auckland: Pfizer New Zealand Ltd.; 2013.

26. Murkin JM, Falter F, Granton J, Young B, Burt C, $\mathrm{Chu} \mathrm{M}$. High-dose tranexamic acid is associated with nonischemic clinical seizures in cardiac surgical patients. Anesth Analg 2010;110:350-3.

27. Ker K, Prieto-Merino D, Roberts I. Systematic review, meta-analysis and meta-regression of the effect of tranexamic acid on surgical blood loss. Br J Surg 2013;100:1271-9.

28. Krohn CD, Sorensen R, Lange JE, Riise R, Bjornsen $S$, Brosstad F. Tranexamic acid given into the wound reduces postoperative blood loss by half in major orthopaedic surgery. Eur J Surg Suppl 2003:57-61.

29. Saberi H, Miri SM, Namdar MP. The effects of topically applied tranexamic acid on reduction of postlaminectomy hemorrhage. Tehran Univ Med J 2010;68:527-33. 